\title{
Relationship between age and bronchodilator response at diagnosis in adult-onset asthma
}

\author{
Minna Tommola ${ }^{1}$ D, Ha-Kyeong Won ${ }^{2}$, Pinja Ilmarinen ${ }^{1}$, Heewon Jung ${ }^{3}$, Leena E. Tuomisto ${ }^{1}$, Lauri Lehtimäki ${ }^{4,5}$, \\ Onni Niemelä ${ }^{5,6}$, Tae-Bum Kim ${ }^{3^{*}}$ and Hannu Kankaanranta ${ }^{1,5^{*}}$
}

\begin{abstract}
Background: Possible variation in bronchodilator response (BDR) according to age at the diagnosis of adult-onset asthma is unknown. Our aim was to assess if $\mathrm{BDR}$ in $\mathrm{FEV}_{1}$ is related to age at diagnosis of adult-onset asthma and how many subjects fulfill the $400 \mathrm{~mL}$ criterion of BDR, the suggested cut-off for asthma-like reversibility in asthmaCOPD overlap (ACO).

Methods: A total of 1030 patients with adult-onset asthma were included; 245 from SAAS (Seinäjoki Adult Asthma Study, Finland) and 785 from COREA (Cohort for Reality and Evolution of Adult Asthma in Korea) cohorts. BDR in $\mathrm{FEV}_{1}$ at the diagnosis of asthma was assessed. Patients were divided into groups based on age at asthma diagnosis: $<40,40-59.9$, and $\geq 60$ years. The cohorts were analyzed separately.

Results: $\mathrm{BDR} \%$ in $\mathrm{FEV}_{1}$ did not differ between the groups of different age at asthma diagnosis and no correlation between BDR and age was found. Of patients aged $\geq 40$ years, only 18\% (SAAS-cohort) and 5\% (COREA-cohort) reached the $400 \mathrm{~mL} \mathrm{BDR}$ in $\mathrm{FEV}_{1}$. After exclusion of possible ACO patients, the results remained similar.
\end{abstract}

Conclusion: By using two large cohorts of steroid-naive patients with asthma, we have shown that BDR at diagnosis of asthma is constant over large age span range, and the limit of $400 \mathrm{~mL}$ in BDR in FEV 1 is rarely reached.

Trial registration: Seinäjoki Adult Asthma Study is registered at ClinicalTrials.gov with identifier number NCT02733016.

Keywords: Adult-onset, Asthma, Cohort study, Bronchodilator response, Asthma-COPD overlap, Spirometry

\section{Introduction}

Asthma is a chronic, heterogeneous disease, characterized by airway inflammation and variable bronchial obstruction [1]. Reversibility in $\mathrm{FEV}_{1}$ of $\geq 12 \%$ and $\geq 200$ $\mathrm{mL}$ after administration of bronchodilator has been regarded significant, and a key finding when diagnosing asthma [1-3]. However, bronchial reversibility has also

\footnotetext{
* Correspondence: tbkim@amc.seoul.kr; hannu.kankaanranta@epshp.fi

${ }^{3}$ Department of Allergy and Clinical Immunology, Asan Medical Center,

University of Ulsan College of Medicine, 88, Olympic-ro 43-gil, Songpa-gu,

Seoul 05505, South Korea

'Department of Respiratory Medicine, Seinäjoki Central Hospital, Hanneksenrinne 7, FIN-60220 Seinäjoki, Finland

Full list of author information is available at the end of the article
}

been reported in COPD [4, 5], although being usually less than $400 \mathrm{~mL}$ in $\mathrm{FEV}_{1}$ [6]. Asthma-COPD overlap (ACO) is a novel recognized phenotype of airways diseases concerning adult patients, but little is still known about ACO and its diagnostics [6-9]. Symptomatic evaluation has been suggested and spirometric features such as $\mathrm{FEV}_{1} / \mathrm{FVC}<0.70$ and a bronchodilator response of at least $12 \%$ or $15 \%$ and $400 \mathrm{~mL}$ have been proposed to be compatible with a diagnosis of ACO in subjects with sufficient smoking history [6, 10-12]. Recently, it has been suggested that a patient with fixed airway obstruction and smoking history compatible with COPD could be considered to have ACO if he/she has either a 
high reversibility of obstruction $\left(>400 \mathrm{~mL}\right.$ BDR in $\mathrm{FEV}_{1}$ ) or a diagnosis of asthma before the age of 40 years [7]. The revised criteria for ACO have already been criticized since the majority of asthma has been reported to be diagnosed after 40 years of age in women [13-16], and a BDR of $\geq 400 \mathrm{~mL}$ in $\mathrm{FEV}_{1}$ in asthma has been shown to detect predominantly young males [17].

There is, unfortunately, lack of high quality evidence on correct cut-off for BDR to distinguish asthmatics from healthy subjects, and even less is known about the ability of BDR to differentiate between asthma, COPD and ACO [3]. Moreover, smoking among patients with asthma is reported to be nearly as common as among healthy population, up to $26 \%$ of asthmatics being smokers [18-20]. This obligates us to pay special attention to the differential diagnostics between asthma, COPD and ACO, especially considering the clinical circumstances where patients have severe symptoms but no previous diagnoses. Previous studies of asthma have usually excluded smoking patients and those with heavy smoking history, and thus, an urgent need for real-life asthma studies including smoking patients has been recognized $[6,20]$.

In reflection to the proposed criteria of $\mathrm{ACO}$, our aim was to evaluate whether BDR varies with age at diagnosis of adult-onset asthma, and how large proportion of patients fulfil the criterion of $400 \mathrm{~mL}$ in BDR, by using data of two, well-described, real-world asthma cohorts.

\section{Methods}

\section{Study population and design}

This study presents the results from two different cohorts of adult-onset asthma patients: Seinäjoki Adult Asthma Study (SAAS) -cohort (Finland), and Cohort for Reality and Evolution of Adult Asthma in Korea (COREA, Korea). Results are presented separately, but in a similar way. Patients in both cohorts are divided into three different age groups: 1) < 40 years, 2) 40-59.9 years, and 3$) \geq 60$ years at asthma diagnosis, respectively.

\section{Seinäjoki adult asthma study (SAAS)}

In Seinäjoki Adult Asthma Study (SAAS), 257 patients ( $\geq 15$ years of age) were diagnosed with new-onset adult asthma during the years 1999-2002 in Seinäjoki Central Hospital, Finland. Diagnosis of asthma was made by respiratory physician, as previously described [9, 21-24]. Majority of the patients were therapy naïve at baseline. Protocol, and the exclusion and inclusion criteria of SAAS have been previously published [21]. A written informed consent was obtained from all patients, and the study protocol was approved by the Ethics committee of Tampere University Hospital, Tampere, Finland (R12122).

In SAAS-cohort, objective lung function measurements were performed on every patient and the diagnosis was based on significant reversibility/variability in obstruction of the airway. BDR of at least $200 \mathrm{~mL}$ and $15 \%$ from baseline value (after inhalation of $200 \mu \mathrm{g}$ of salbutamol) was considered diagnostic for asthma but diagnosis could also be based on peak expiratory flow (PEF) monitoring, bronchial obstruction in response to challenge with allergen or exercise, or reversibility of obstruction with steroid therapy [21]. In the present study, all patients $(n=245)$ with bronchodilator test performed at the time of diagnosis are included, and cross-sectional data from the diagnostic visit is used. Finnish reference values of spirometry were used [25].

\section{Cohort for reality and evolution of adult asthma Korea (COREA)}

The Cohort for Reality and Evolution of Adult Asthma (COREA) is the first asthma cohort in South Korea since 2005 [16, 26-31]. Patients (aged $\geq 15$ years) diagnosed with asthma by allergists or pulmonologists from 21 centers in diverse areas of Korea were enrolled to the study. In COREA, inclusion criteria were a diagnosis of asthma based on clinical symptoms and either a positive bronchodilator test $(200 \mu \mathrm{g}$ of salbutamol) or airway hyperresponsiveness $\left(\mathrm{PC}_{20} \mathrm{FEV}_{1} \leq 25 \mathrm{mg} / \mathrm{ml}\right.$ methacholine). All enrolled participants signed informed consent. The protocol and design of this cohort were approved by the institutional review board of each center. Of the original 4846 asthma patients in COREA cohort, our study selected a total of 785 patients who were steroid naïve, and had a bronchodilator test performed at the time of diagnosis. In COREA cohort generally, diagnosis of asthma was based on patients having either BDR of at least $200 \mathrm{~mL}$ and $12 \%$ in spirometry, or at least moderate bronchial hyperreactivity. Majority of the diagnoses in COREA cohort were based on methacholine challenge test.

In both cohorts, smoking status and history were assessed and smoked pack-years (20 cigarettes per day for 1 year) were evaluated. Levels of blood eosinophils and immunoglobulin E (IgE) were measured, skin prick tests were performed, and the use of steroid medication was recorded by a structured questionnaire.

\section{Statistical analyses}

Statistical analyses were performed using SPSS software, version 24 (IBM SPSS, Armonk, NY) or R software, version 3.5.0. Continuous data is expressed as mean $\pm \mathrm{SD}$ or median and interquartile range, as appropriate. Groups were compared by using one-way ANOVA with Tukey's post hoc test, Kruskal-Wallis test or $\chi^{2}$-test. Correlation analyses were performed by using Spearman's or Pearson's correlation tests. A $p$-value $<0.05$ was regarded as statistically significant. 


\section{Results}

\section{Clinical characteristics by age in SAAS cohort}

There were no differences in gender distribution between the 3 groups with different age at asthma diagnosis, but BMI increased by age (Table 1). Majority of patients in all age groups were never smokers, and the proportion of current smokers decreased with age. As expected, the number of pack-years (among ex and current smokers) increased by age, being highest in the oldest group. Majority of the patients were therapy naive at the diagnosis of asthma, with $<9 \%$ using steroid medication at that time. Furthermore, there were no differences in the levels of blood eosinophils or immunoglobulin E (IgE) between the groups, although the number of atopic patients was found to be significantly higher in the youngest age group $(<40$ years) as compared to the older groups (Table 1).

\section{Clinical characteristics by age in the COREA cohort}

Patients with asthma onset $\geq 60$ years were more often males, and BMI increased with increasing age of asthma diagnosis (Table 2). Majority of patients in the two groups with asthma diagnosis before 60 years of age were never smokers, but in the oldest group ( $\geq 60$ years) most patients were ex-smokers. Number of smoked pack-years increased with age at diagnosis, as expected. Blood eosinophil levels and prevalence of atopy were the highest among patients with youngest age at diagnosis of asthma (Table 2). No differences in IgE levels were found between the groups of different age at diagnosis of asthma (Table 2). All patients included from the COREA cohort were steroid-naive at the diagnosis of asthma.
Lung function by age in cohorts of SAAS and COREA

In both cohorts, lung function as measured in liters and percentages of predicted value at the time of diagnosis was found to decrease by age (Table 3 ). In addition, the severity of obstruction, as measured by $\mathrm{FEV}_{1} / \mathrm{FVC}$ ratio, increased by age. In contrast, no differences were found between the groups in the diffusing capacity values, which were measured only in the SAAS-cohort (Table $3)$. Both the cohorts of SAAS and COREA included also smoking patients (ex or current) and therefore some patients could be considered as having ACO. The proportion of possible ACO patients, i.e. subjects with smoking history of $\geq 10$ pack-years and post-bronchodilator $\mathrm{FEV}_{1} /$ FVC $<0.7$, increased by age. Of the patients in the oldest groups, $22 \%$ in the SAAS cohort and $37 \%$ in the COREA cohort fulfilled the ACO criteria (Table 3).

\section{Bronchodilator response by age in SAAS cohort}

Bronchodilator reversibility in $\mathrm{FEV}_{1}$ (absolute change in $\mathrm{mL}$, and change in \% from the baseline value) was measured at the time of asthma diagnosis in every patient included in the analysis. No significant differences were found between the age groups in $\mathrm{FEV}_{1} \mathrm{BDR}$ measured either as $\mathrm{mL}$ or percentages (Table 4). In addition, the proportion of patients having high reversibility of obstruction ( $>400 \mathrm{~mL}$ in $\mathrm{FEV}_{1}$ ) did not differ between the age groups (Table 4). The findings remained the same even after exclusion of possible ACO patients (Supplementary Table S1). Furthermore, there were no differences between the age groups in the proportions of patients who fulfilled the reversibility criteria of $200 \mathrm{~mL}$, $12 \%$ or both (Table 4 ).

Table 1 Baseline clinical characteristics of the 245 patients included from the SAAS cohort

\begin{tabular}{|c|c|c|c|c|}
\hline & $\begin{array}{l}\text { Age at asthma diagnosis } \\
<40 \text { years } \\
n=83\end{array}$ & $\begin{array}{l}\text { Age at asthma diagnosis } \\
\text { 40-59.9 years } \\
n=115\end{array}$ & $\begin{array}{l}\text { Age at asthma diagnosis } \\
\geq 60 \text { years } \\
n=47\end{array}$ & $p$-value \\
\hline Age, years & $29.2 \pm 7.0$ & $50.6 \pm 5.3$ & $68.0 \pm 5.3$ & NA \\
\hline Gender male & 33 (39.8\%) & 48 (41.7\%) & $22(46.8 \%)$ & 0.733 \\
\hline $\mathrm{BMI} \mathrm{kg} \cdot \mathrm{m}^{-2}$ & $25.5(23.1-30.0)$ & $27.1(24.3-30.1)$ & $28.7(26.4-31.6)^{a}$ & 0.006 \\
\hline Smoking status & & & & 0.003 \\
\hline Never smokers & $46(55.4 \%)$ & $49(42.6 \%)$ & $23(48.9 \%)$ & \\
\hline Ex-smokers & $14(16.9 \%)$ & $43(37.4 \%)^{a}$ & $20(42.6 \%)^{a}$ & \\
\hline Current smokers & $23(27.7 \%)$ & $23(20.0 \%)$ & $4(8.5 \%)^{a}$ & \\
\hline Pack-years (of ex/current smokers) & $5(3-18)$ & $15(7-20)^{a}$ & $24(10-38)^{a, b}$ & $<0.001$ \\
\hline Steroid medication in use & $4(4.9 \%)$ & $10(8.7 \%)$ & $4(8.5 \%)$ & 0.582 \\
\hline B-eosinophils $\times 10^{9} / \mathrm{L}$ & $0.30(0.19-0.46)$ & $0.22(0.16-0.40)$ & $0.24(0.18-0.45)$ & 0.341 \\
\hline $\lg E \mathrm{kU} / \mathrm{L}^{\mathrm{c}}$ & $98(38-237)$ & $75(28-145)$ & $71(21-138)$ & 0.108 \\
\hline Skin prick positive & $41(54.7 \%)$ & $30(29.1 \%)^{a}$ & $6(14.6 \%)^{a}$ & $<0.001$ \\
\hline
\end{tabular}

Data is shown as $\mathrm{n}(\%)$, mean $\pm \mathrm{SD}$, or median (interquartile range). $N A$ not analyzed, $B M l$ body mass index, $B$ blood, lgE immunoglobulin $\mathrm{E}$

${ }^{a}$ : as compared to group: Age at asthma diagnosis $<40$ years $p<0.05$

b as compared to group: Age at asthma diagnosis $40-59.9$ years $p<0.05$

c: data available on 187 patients 
Table 2 Baseline clinical characteristics of the 785 patients included from the COREA cohort

\begin{tabular}{|c|c|c|c|c|}
\hline & $\begin{array}{l}\text { Age at asthma diagnosis } \\
<40 \text { years } \\
n=245\end{array}$ & $\begin{array}{l}\text { Age at asthma diagnosis } \\
40-59.9 \text { years } \\
n=316\end{array}$ & $\begin{array}{l}\text { Age at asthma diagnosis } \\
\geq 60 \text { years } \\
n=224\end{array}$ & $p$-value \\
\hline Age, years & $36.3 \pm 11.6$ & $54.4 \pm 7.8$ & $68.9 \pm 5.3$ & NA \\
\hline Gender male & $103(42.0 \%)$ & $141(44.6 \%)$ & $118(52.7 \%)$ & 0.055 \\
\hline $\mathrm{BMI} \mathrm{kg} \cdot \mathrm{m}^{-2}$ & $23.3 \pm 3.6$ & $24.6 \pm 3.5^{a}$ & $24.6 \pm 3.1^{\mathrm{a}}$ & $<0.001$ \\
\hline \multicolumn{5}{|l|}{ Smoking status } \\
\hline never smokers & $116(48.5 \%)$ & $171(55.2 \%)$ & $94(42.9 \%)$ & \multirow[t]{3}{*}{$<0.001$} \\
\hline ex-smokers & $83(34.3 \%)$ & $100(31.3 \%)$ & $106(48.4 \%)$ & \\
\hline current smokers & $41(17.2 \%)$ & $42(13.6 \%)$ & 19 (8.7\%) & \\
\hline Pack-years & $4 \pm 9$ & $9 \pm 16^{a}$ & $17 \pm 24^{a, b}$ & $<0.001$ \\
\hline B-eosinophils $\times 10^{9} / \mathrm{L}$ & $0.44 \pm 0.40$ & $0.33 \pm 0.32^{\mathrm{a}}$ & $0.28 \pm 0.26^{a}$ & $<0.001$ \\
\hline $\lg E \mathrm{kU} / \mathrm{L}^{\mathrm{c}}$ & $422 \pm 568$ & $320 \pm 576$ & $378 \pm 650$ & 0.305 \\
\hline Skin prick positive ${ }^{d}$ & $115(64.6 \%)$ & $85(47.0 \%)$ & $18(19.2 \%)$ & $<0.001$ \\
\hline
\end{tabular}

Data is shown as $\mathrm{n}(\%)$ and mean $\pm \mathrm{SD}$. NA not analyzed, $B M I$ body mass index, $B$ blood, $\lg E$ immunoglobulin $\mathrm{E}$

${ }^{a}$ : as compared to group: Age at asthma diagnosis $<40$ years $p<0.05$

${ }^{\mathrm{b}}$ as compared to group: Age at asthma diagnosis 40-59.9 years $p<0.05$.

c: data available on 461 patients. ${ }^{d}$ : data available on 463 patients

\section{Bronchodilator response by age in COREA cohort}

Bronchodilator reversibility was higher in patients with younger age at diagnosis when measured as absolute change (mL) in $\mathrm{FEV}_{1}$, but not when measured as \% change from the baseline value (Table 5). Percentage of patients with absolute (either $>400 \mathrm{~mL}$ or $\geq 200 \mathrm{~mL}$ ) change in $\mathrm{FEV}_{1}$ was the highest in the youngest group ( $<40$ years).
However, no differences were found between the groups in the proportions of patients who fulfilled $\geq 12 \%$, or $\geq 12 \%$ and $\geq 200 \mathrm{~mL}$ of BDR in $\mathrm{FEV}_{1}$ (Table 5). After exclusion of possible ACO patients, BDR in $\mathrm{FEV}_{1}$ did not differ between the age groups either in $\mathrm{mL}$ or in \%, and proportion of patients with $>400 \mathrm{~mL}$ BDR in $\mathrm{FEV}_{1}$ decreased with age (Supplementary Table S2).

Table 3 Lung function and prevalence of ACO in cohorts of SAAS and COREA

\begin{tabular}{|c|c|c|c|c|}
\hline & $\begin{array}{l}\text { Age at asthma diagnosis } \\
<40 \text { years }\end{array}$ & $\begin{array}{l}\text { Age at asthma diagnosis } \\
40-59.9 \text { years }\end{array}$ & $\begin{array}{l}\text { Age at asthma diagnosis } \\
\geq 60 \text { years }\end{array}$ & $p$-value \\
\hline \multicolumn{5}{|l|}{ SAAS cohort } \\
\hline $\mathrm{FEV}_{1} \mathrm{~L}$ post BD & $3.34(2.90-4.17)$ & $2.87(2.40-3.36)^{a}$ & $2.01(1.75-2.50)^{a, b}$ & $<0.001$ \\
\hline $\mathrm{FEV}_{1} \%$ pred post BD & $90(84-100)$ & 86 (74-99) & 79 (60-89) a,b & $<0.001$ \\
\hline $\mathrm{FEV}_{1} / \mathrm{FVC}$ post $\mathrm{BD}$ & $0.81(0.75-0.87)$ & $0.78(0.73-0.83)^{a}$ & $0.73(0.62-0.79)$ a,b & $<0.001$ \\
\hline FVC $\%$ pred post BD & $95(88-103)$ & $92(78-103)$ & $87(73-98)^{a}$ & 0.012 \\
\hline DLco \% predicted ${ }^{c}$ & $100 \pm 20$ & $95 \pm 19$ & $92 \pm 18$ & 0.093 \\
\hline DLNA \% predicted ${ }^{c}$ & $104 \pm 19$ & $98 \pm 19$ & $97 \pm 15$ & 0.106 \\
\hline $\mathrm{ACO}^{\mathrm{d}}$ & $3(3.7 \%)$ & $11(9.7 \%)$ & $10(22.2 \%)^{a}$ & 0.004 \\
\hline \multicolumn{5}{|l|}{ COREA cohort } \\
\hline $\mathrm{FEV}_{1} \mathrm{~L}$ post BD & $2.74 \pm 0.90$ & $2.23 \pm 0.69^{a}$ & $1.70 \pm 0.57^{a, b}$ & $<0.001$ \\
\hline $\mathrm{FEV}_{1} \%$ pred post BD & $84 \pm 21$ & $82 \pm 23$ & $75 \pm 24^{a, b}$ & $<0.001$ \\
\hline $\mathrm{FEV}_{1} / \mathrm{FVC}$ post $\mathrm{BD}$ & $0.77 \pm 0.13$ & $0.72 \pm 0.13^{a}$ & $0.66 \pm 0.15^{a, b}$ & $<0.001$ \\
\hline FVC\% pred post BD & $90 \pm 16$ & $90 \pm 17$ & $84 \pm 21^{a, b}$ & $<0.001$ \\
\hline $\mathrm{ACO}^{\mathrm{d}}$ & $17(6.9 \%)$ & 55 (17.4\%) & $82(36.6 \%)$ & $<0.001$ \\
\hline
\end{tabular}

Data is shown as $\mathrm{n}(\%)$, mean $\pm \mathrm{SD}$ or median (interquartile range). DLco Diffusing capacity of the lung for carbon monoxide, VA Alveolar volume

a: as compared to group: Age at asthma diagnosis $<40$ years $p<0.05$

$\mathrm{b}$ as compared to group: Age at asthma diagnosis 40-59.9 years $p<0.05$

${ }^{c}$ Data available from $64(77.1 \%), 86(74.8 \%)$ and $33(70.2 \%)$ of patients, respectively

${ }^{\mathrm{d} A C O}$ : post $\mathrm{BD} \mathrm{FEV}_{1} / \mathrm{FVC}<0.7$ and pack-years $\geq 10$ 
Table 4 Bronchodilator response in $\mathrm{FEV}_{1}$ at asthma diagnosis by age groups in SAAS cohort

\begin{tabular}{|c|c|c|c|c|}
\hline & $\begin{array}{l}\text { Age at asthma diagnosis } \\
<40 \text { years } \\
n=83\end{array}$ & $\begin{array}{l}\text { Age at asthma diagnosis } \\
40-59.9 \text { years } \\
n=115\end{array}$ & $\begin{array}{l}\text { Age at asthma diagnosis } \\
\geq 60 \text { years } \\
n=47\end{array}$ & $p$-value \\
\hline $\mathrm{FEV}_{1} \mathrm{BDR} \mathrm{mL}$ & $190(100-330)$ & $130(60-340)$ & $180(30-310)$ & 0.266 \\
\hline $\mathrm{FEV}_{1} \mathrm{BDR} \%$ & $6.1(3.1-11.2)$ & $5.5(1.9-12.1)$ & $8.9(2.1-20.6)$ & 0.293 \\
\hline Patients with $>400 \mathrm{~mL} \mathrm{BDR}$ in $\mathrm{FEV}_{1}$ & $15(18.1 \%)$ & $23(20.0 \%)$ & $6(12.8 \%)$ & 0.553 \\
\hline Patients with $\geq 200 \mathrm{~mL}$ BDR in $\mathrm{FEV}_{1}$ & $41(49.4 \%)$ & $46(40.0 \%)$ & $20(42.6 \%)$ & 0.415 \\
\hline Patients with $\geq 12 \%$ BDR in $\mathrm{FEV}_{1}$ & $18(21.7 \%)$ & $29(25.2 \%)$ & $18(38.3 \%)$ & 0.109 \\
\hline Patients with $\geq 200 \mathrm{~mL}$ and $12 \%$ BDR in $\mathrm{FEV}_{1}$ & $18(21.7 \%)$ & $29(25.2 \%)$ & $17(36.2 \%)$ & 0.187 \\
\hline
\end{tabular}

Data is shown as $\mathrm{n}$ (\%) or median (interquartile range). $B D R$ bronchodilator response

\section{Correlation between age at asthma diagnosis and bronchodilator response}

To further evaluate the connection between age at asthma diagnosis and bronchial reversibility, correlations were analyzed. No correlation was found between BDR in $\mathrm{FEV}_{1}$ in $\%$ and age at asthma diagnosis in either of the cohorts (Fig. $1 \mathrm{~b}$ and d). Age at asthma diagnosis and $\mathrm{FEV}_{1} \mathrm{BDR}$ in $\mathrm{mL}$ showed statistically, but not clinically, significant negative correlation (i.e. higher reversibility in younger subjects) in COREA cohort (Fig. 1c), but not in SAAS cohort (Fig. 1a).

\section{Discussion}

We present here the results on bronchodilator response in patients at the time of diagnosis of adult-onset asthma, as measured in two different, carefully described, clinical cohorts of asthma: the Seinäjoki Adult Asthma Study (SAAS) and the Cohort for Reality and Evolution of Adult Asthma in Korea (COREA). BDR as measured in \% in $\mathrm{FEV}_{1}$ was shown to be similar in different ages of asthma diagnosis. In addition, the majority of patients aged 40 years or older, did not reach the BDR limit of $400 \mathrm{~mL}$ in $\mathrm{FEV}_{1}$ at the diagnostic time of asthma.

As previously shown, lung function decreased with age in both cohorts [32-35]. BDR has been previously proposed to decrease with age among general population and healthy persons [32, 33, 36]. A study of Quanjer et al. evaluated the change in $\mathrm{FEV}_{1}$ after bronchodilator on obstructive clinical patients (asthma, COPD or $\mathrm{ACO}$ ), and showed association of BDR with age, height, sex and level of respiratory impairment [36]. The change in $\mathrm{FEV}_{1}$ was suggested to decline with age, becoming even negative after 50 years of age [36]. Another recent population study on subjects with treated asthma and COPD reported a very limited value of reversibility testing in distinguishing asthma from COPD [37]. In addition, a recent review on BDR in asthma diagnostics stated that the change in $\mathrm{FEV}_{1}$ after bronchodilator may not be very sensitive tool in asthma diagnostics, and the sensitivity or specificity of any cut-off levels have not been clearly shown [3]. Our study on adult-onset asthma patients showed the relative response to bronchodilator in $\mathrm{FEV}_{1}$ (\% from baseline) to be similar despite the age at diagnosis of asthma, and absolute BDR in $\mathrm{FEV}_{1}(\mathrm{~mL})$ to decrease with increasing age of asthma diagnosis. In keeping with the previous studies, our results thus showed, that BDR in $\mathrm{FEV}_{1}$ does not increase after age of 40 years. In addition, correlation analyses between age and $\mathrm{BDR}$ in $\mathrm{FEV}_{1}$ did not show clinically meaningful correlation, further indicating that BDR remains stable despite increasing age of asthma onset.

Table 5 Bronchodilator response in $\mathrm{FEV}_{1}$ at asthma diagnosis by age groups in COREA cohort

\begin{tabular}{|c|c|c|c|c|}
\hline & $\begin{array}{l}\text { Age at asthma diagnosis } \\
<40 \text { years } \\
n=245\end{array}$ & $\begin{array}{l}\text { Age at asthma diagnosis } \\
40-59.9 \text { years } \\
n=316\end{array}$ & $\begin{array}{l}\text { Age at asthma diagnosis } \\
\geq 60 \text { years } \\
n=224\end{array}$ & $p$-value \\
\hline $\mathrm{FEV}_{1} \mathrm{BDR} \mathrm{mL}$ & $153 \pm 268$ & $139 \pm 192$ & $101 \pm 175^{a}$ & $<0.001$ \\
\hline $\mathrm{FEV}_{1} \mathrm{BDR} \%$ & $7.9 \pm 14.1$ & $8.4 \pm 12.8$ & $8.6 \pm 13.9$ & 0.631 \\
\hline Patients with $>400 \mathrm{~mL}$ BDR in FEV & $37(15.1 \%)$ & $20(6.3 \%)^{a}$ & $9(4.0 \%)^{\mathrm{a}}$ & $<0.001$ \\
\hline Patients with $\geq 200 \mathrm{~mL}$ BDR in $\mathrm{FEV}_{1}$ & $95(38.8 \%)$ & $104(32.9 \%)$ & $49(21.9 \%)^{a, b}$ & $<0.001$ \\
\hline Patients with $\geq 12 \%$ BDR in $\mathrm{FEV}_{1}$ & $58(23.7 \%)$ & $94(29.8 \%)$ & $73(32.6 \%)$ & 0.088 \\
\hline Patients with $\geq 200 \mathrm{~mL}$ and $12 \% \mathrm{BDR}$ in $\mathrm{FEV}_{1}$ & $55(22.5 \%)$ & 79 (25.0\%) & $46(20.5 \%)$ & 0.467 \\
\hline
\end{tabular}

Data is shown as $\mathrm{n}(\%)$ and mean $\pm \mathrm{SD}$.

a: as compared to group: Age at asthma diagnosis $<40$ years $p<0.05$

${ }^{b}$ as compared to group: Age at asthma diagnosis $40-59.9$ years $p<0.05$ 


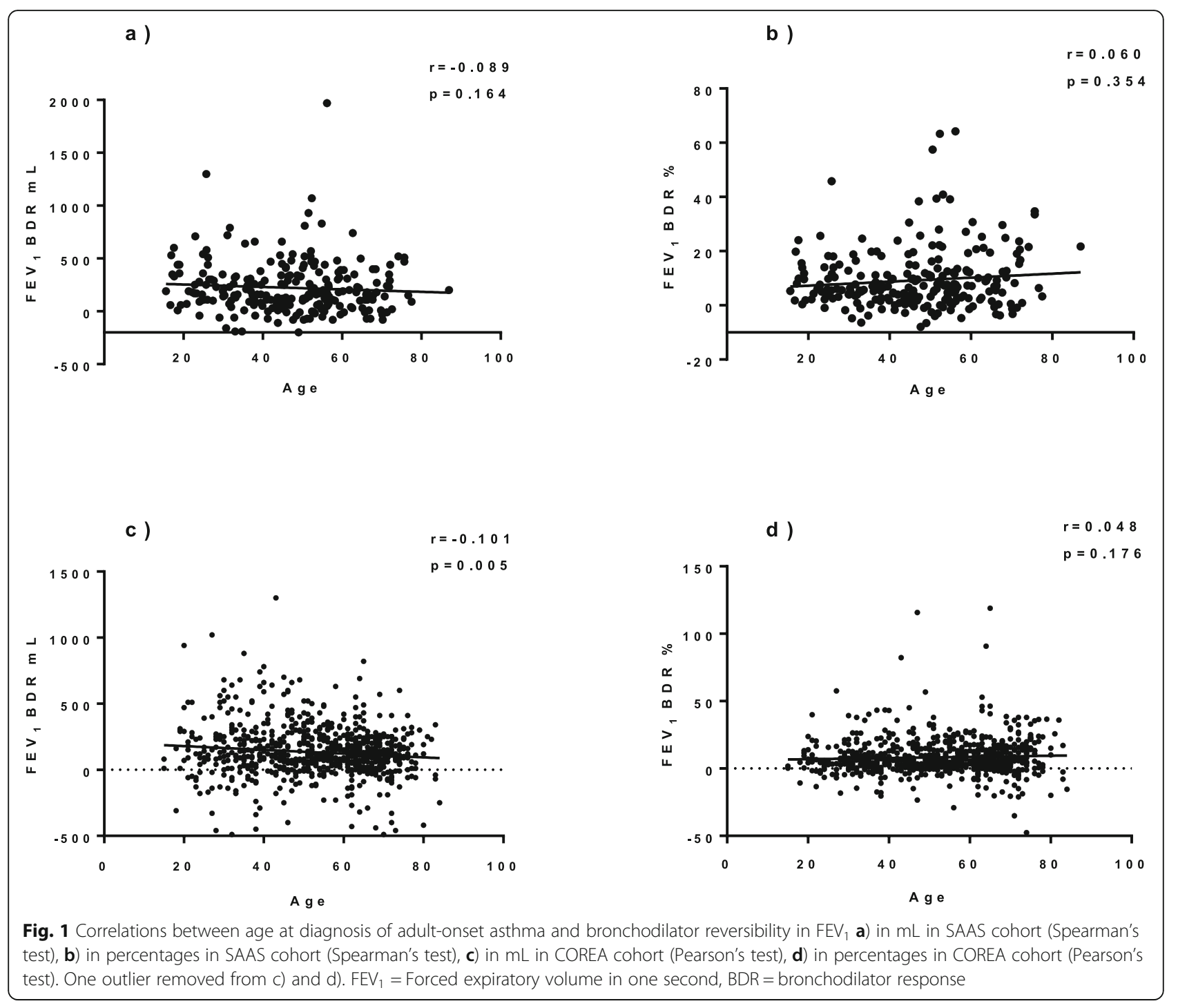

Increasing evidence shows that asthma starting at adult age is very common [14-16]. As compared with child-onset disease, adult-onset asthma patients are less often allergic and have poorer prognosis with low remission rate $[24,38]$. At adult age the differential diagnostics between asthma, ACO and COPD becomes essential, because misdiagnosing adult smoking patients' asthma or ACO for COPD may lead to severe morbidity on individual level. However, widely accepted diagnostic criteria for ACO are still missing.

Several COPD guidelines have presented suggestions for ACO criteria [10-12]. Major proposed criteria for ACO among population with COPD have been a significant BDR in $\mathrm{FEV}_{1}(>15 \%$ and $>400 \mathrm{~mL}$ ), sputum eosinophilia and elevated levels of exhaled nitric oxide (FeNO) [10-12]. Further proposal for ACO criteria has included an age cut-off of 40 years: asthma should be diagnosed earlier, or high reversibility in $\mathrm{FEV}_{1}>400 \mathrm{~mL}$ should be present [7]. There are, however, different pathways in developing asthma-COPD overlap. The most studied perspective is when a patient has a previous diagnosis of COPD and develops ACO afterwards; a viewpoint widely reflected in the previous guidelines and suggestions for ACO criteria [7, 10-12]. However, ACO may also become diagnosed in patients with previous asthma or, more importantly, in patients without any previous diagnoses. This perspective is only remotely studied, even though the implementation challenges of the previously suggested ACO criteria among general population have already been discussed [13].

Our results showed, that BDR \% in $\mathrm{FEV}_{1}$ does not change with age, and even fewer asthma patients have $>$ $400 \mathrm{~mL}$ of BDR in $\mathrm{FEV}_{1}$ at the diagnostic point when age of asthma-onset increases. As partial reversibility of the obstruction is also a feature of COPD, the suggested limit of $>400 \mathrm{~mL}$ BDR in $\mathrm{FEV}_{1}$ for asthma-COPD 
overlap diagnosis after 40 years of age would presumably reduce the overuse of inhaled corticosteroids. The high BDR cut-off would improve specificity, but on the cost of sensitivity. In practice, this means that a majority of subjects with new onset adult asthma as component of their ACO would have to fulfil this strict criterion of reversibility. In our study, of the patients aged 40 years or older at the time of asthma diagnosis, only $5 \%$ in COREA cohort and $18 \%$ in SAAS cohort fulfilled the limit of BDR $>400 \mathrm{~mL}$ in $\mathrm{FEV}_{1}$. That is to say, 82-95\% of the adult-onset asthma patients do not reach the limit of $\mathrm{BDR}>400 \mathrm{~mL}$ in $\mathrm{FEV}_{1}$. In addition, atopy was shown to decrease with age, in keeping with previous studies [39]. Thus, if using the suggested $>400 \mathrm{~mL}$ limit in nonatopic patients for asthma-COPD overlap diagnosis, most adult-onset ACO diagnoses would be missed.

In COPD it has been shown that BDR in $\mathrm{FEV}_{1}$ decreases with increasing severity of COPD $[4,5]$. In our study, some patients with smoking history $\geq 10$ packyears and post $\mathrm{BD} \mathrm{FEV} / \mathrm{FVC}<0.7$ could be considered as having asthma-COPD overlap, although the spirometry was measured before the start of the asthma therapy. To avoid bias caused by possible ACO patients having presumably lower response to bronchodilator, we further performed analyses with exclusion of possible ACO patients. The main result remained the same, and thus, our finding is not biased by ACO or COPD.

Major strength of the current study is that we have two large, well defined, real-world cohorts of adult-onset asthma, altogether a study population reflecting clinical reality exceptionally well. The large number of enrolled patients enables us to examine the BDR at the moment of asthma diagnosis in patients over the whole adult-age span, without losing power in analyses. Patients with smoking history are included in the study cohorts, and smoking intensity of the patients is well described. In accordance to the guidelines, the diagnosis of asthma was based on clinical history and objective lung function measurements, and bronchodilator test was measured in every patient. In SAAS and COREA cohorts, however, the diagnostic practices differ slightly from one another. In some patients, the diagnosis of asthma was made based on other objective lung function measurements than positive bronchodilation test, leading to somewhat lower BDR results. This could be considered as a limitation. Despite this, the level of change in $\mathrm{FEV}_{1}$ after administration of a bronchodilator was similar in these cohorts and the results of both cohorts are in line, increasing the reliability of our results. The reversibility status of individual patients has been shown to vary over time $[4,5]$. Thus, another limitation of our study could be that only the BDR at the diagnostic point of asthma was evaluated. However, in our study, most patients were steroid naïve at the diagnostic visit and inhaled corticosteroid medication was started after diagnostic measures. Therefore, evaluating BDR in several time points in our study would not have been informative.

\section{Conclusions}

In conclusion, we have shown that the BDR in $\mathrm{FEV}_{1}$ at asthma diagnosis is constant over large age span range in adult-onset asthma. In addition, minority of patients with adult-onset asthma have $>400 \mathrm{~mL}$ BDR in $\mathrm{FEV}_{1}$ at time of diagnosis. These findings are to be considered when designing diagnostic guidelines concerning asthma starting at adult age, including asthma-COPD overlap.

\section{Supplementary information}

Supplementary information accompanies this paper at https://doi.org/10. 1186/s12931-020-01441-w.

Additional file 1: Table S1. Bronchodilator response (BDR) in FEV grouped by age at asthma diagnosis in SAAS cohort after exclusion of ACO patients. Table S2. Bronchodilator response (BDR) in $\mathrm{FEV}_{1}$ grouped by age at asthma diagnosis in COREA cohort after exclusion of ACO patients.

\section{Abbreviations}

$\mathrm{FEV}_{1}$ : Forced expiratory volume in one second; FVC: Forced vital capacity; COPD: Chronic obstructive pulmonary disease; ACO: Asthma-COPD overlap; BDR: Bronchodilator response; SAAS: Seinäjoki Adult Asthma Study;

COREA: Cohort for Reality and Evolution of Adult Asthma in Korea; PEF: Peak expiratory flow; $\mathrm{PC}_{20} \mathrm{FEV}_{1}$ : Provocative concentration causing a $20 \%$ fall in forced expiratory volume in one second; IgE: Immunoglobulin E; BMI: Body mass index; DLco: Diffusing capacity of the lung for carbon monoxide; DL/ VA: Diffusing capacity of the lung/ alveolar volume

\section{Acknowledgements}

We are grateful to Aino Sepponen, RN, for her input with data management We thank the members of the study centers for participating in this study. The COREA Study Group includes the following investigators: Tae-Bum Kim, Woo-Jung Song, Hyouk-Soo Kwon, and You Sook Cho (University of Ulsan, Seoul, Korea); Sae-Hoon Kim (Bundang Seoul National University, Seongnam, Korea); Byoung Whui Choi and Jae-Woo Jung (Chung-Ang University, Seoul, Korea); Young-Joo Cho and Min-Hye Kim (Ewha Womans University, Seoul, Korea); An-Soo Jang (Soonchunhyang University, Bucheon, Korea); Yoo Seob Shin (Ajou University, Suwon, Korea); Ji-Yong Moon (Hanyang University, Guri, Korea), Jae-Woo Kwon (Kangwon National University, Chuncheon, Korea); Sang-Hoon Kim and So Young Park (Eulji University, Seoul, Korea); Taehoon Lee (University of Ulsan, Ulsan, Korea); Sujeong Kim (Kyungpook National University, Daegu, Korea); Chan Sun Park (Inje University, Haeundae Paik Hospital, Busan, Korea); Joo-Hee Kim (Hallym University, Sacred Heart Hospital, Anyang, Korea); Jeong-Hee Choi (Hallym University, Dongtan Sacred Heart Hospital, Hwaseong, Korea); Young-Hee Nam (Dong-A University, Busan, Korea); Sun-Young Yoon (University of Konkuk, Chungju, Korea); Hyun Jung Jin (Yeungnam University, Daegu, Korea); Min-Suk Yang (Seoul National University, Boramae Medical Center, Seoul, Korea); Jaechun Lee (Jeju National University, Jeju, Korea); Hye-Kyung Park (Pusan National University, Busan, Korea); Gyu Young Hur (Korea University, Seoul, Korea); Hee-Kyoo Kim (Kosin University, Busan, Korea); and Sang Ha Kim (Yonsei University, Wonju, Korea).

\section{Authors' contributions}

M.T, P. I, L.E.T, L.L. H.K.W., .-B.K. and H.K. designed the study and wrote the report with input from the other authors. M.T, H.J, and H.K.W. performed the statistical analyses. O.N. contributed to the laboratory analyses. All authors contributed to interpretation of the data. All authors made critical revisions of the manuscript and approved the final version of the manuscript. 


\section{Funding}

Supported by the Finnish Anti-Tuberculosis Association Foundation (Helsinki, Finland), Tampere Tuberculosis Foundation (Tampere, Finland), the Research Foundation of the Pulmonary Diseases (Helsinki, Finland), Orion Research Foundation (Espoo, Finland), the Competitive State Research Financing of the Expert Responsibility Area of Tampere University Hospital (Tampere, Finland), the Medical Research Fund of Seinäjoki Central Hospital (Seinäjoki, Finland) and the Korea Health Technology R\&D Project through the Korea Health Industry Development Institute (KHIDI), funded by the Ministry of Health \& Welfare, Republic of Korea (grant number: HC15C1335). None of the sponsors had any involvement in the planning, execution, drafting or write-up of this study.

\section{Availability of data and materials}

All data generated or analyzed during this study are included in this published article (and its Supplementary File). According to ethical permission and patient data-protection laws of Finland, single patient data cannot be made available, but aggregated data is available from authors on reasonable request.

\section{Ethics approval and consent to participate}

All enrolled participants in COREA cohort and in SAAS cohort signed informed consent. The protocol and design of COREA cohort were approved by the institutional review board of each center. The study protocol of SAAS was approved by the Ethics committee of Tampere University Hospital, Tampere, Finland (R12122)

\section{Competing interests}

Dr. Tommola reports personal fees from Astra Zeneca, personal fees from Boehringer ingelheim, personal fees from Pfizer, grants from Orion research foundation, personal fees from Chiesi, outside the submitted work. Dr. Won has nothing to disclose. Dr. IImarinen reports grants and personal fees from Astra Zeneca, personal fees from Mundipharma, personal fees from GlaxoSmithKline, personal fees from Orion, personal fees from Novartis, outside the submitted work. Dr. Jung has nothing to disclose. Dr. Tuomisto reports non-financial support from Chiesi, non-financial support from Boehringer-Ingelheim, personal fees from Astra Zeneca, non-financial support from Orion Pharma, non-financial support from TEVA, other from Novartis, outside the submitted work. Dr. Lehtimäki reports personal fees from ALK, personal fees from AstraZeneca, personal fees from Boehringer Ingelheim, personal fees from Chiesi, personal fees from GSK, personal fees from Mundipharma, personal fees from Novartis, personal fees from OrionPharma, outside the submitted work. Dr. Niemelä has nothing to disclose. Dr. Kankaanranta reports grants, personal fees and non-financial support from AstraZeneca, personal fees from Chiesi Pharma AB, personal fees and nonfinancial support from Boehringer-Ingelheim, personal fees from Novartis, personal fees from Mundipharma, personal fees and non-financial support from Orion Pharma, personal fees from SanofiGenzyme, personal fees from GlaxoSmithKline, outside the submitted work. Dr. Kim has nothing to disclose.

\section{Author details}

'Department of Respiratory Medicine, Seinäjoki Central Hospital, Hanneksenrinne 7, FIN-60220 Seinäjoki, Finland. ${ }^{2}$ Department of Internal Medicine, VHS Medical Center, Seoul, South Korea. ${ }^{3}$ Department of Allergy and Clinical Immunology, Asan Medical Center, University of Ulsan College of Medicine, 88, Olympic-ro 43-gil, Songpa-gu, Seoul 05505, South Korea. ${ }^{4}$ Allergy Centre, Tampere University Hospital, Tampere, Finland. ${ }^{5}$ Faculty of Medicine and Health Technology, Tampere University, Tampere, Finland. ${ }^{6}$ Department of Laboratory Medicine and Medical Research Unit, Seinäjoki Central Hospital, Seinäjoki, Finland.

Received: 14 November 2019 Accepted: 6 July 2020

\section{Published online: 13 July 2020}

\section{References}

1. Global Initiative for Asthma: Global Strategy for Asthma Management and Prevention. Updated 2018. http://www.ginasthma.org/. Date last accessed: 26 Feb 2019.

2. Pellegrino R, Viegi G, Brusasco V, Crapo RO, Burgos F, Casaburi R, Coates A van der Grinten CP, Gustafsson P, Hankinson J, Jensen R, Johnson DC,
Maclntyre N, McKay R, Miller MR, Navajas D, Pedersen OF, Wanger J. Interpretative strategies for lung function tests. Eur Respir J. 2005;26:948-68.

3. Tuomisto $L E$, Ilmarinen $P$, Lehtimäki L, Tommola $M$, Kankaanranta $H$. Immediate bronchodilator response in $\mathrm{FEV}_{1}$ as a diagnostic criterion for adult asthma. Rev Eur Respir J. 2019;53. https://doi.org/10.1183/13993003. 00904-2018.

4. Hanania NA, Celli BR, Donohue JF, Martin UJ. Bronchodilator reversibility in COPD. Chest. 2011;140:1055-63.

5. Calverley PM, Albert P, Walker PP. Bronchodilator reversibility in chronic obstructive pulmonary disease: use and limitations. Lancet Respir Med. 2013;1:564-73

6. Global Initiative for Asthma and Global Initiative for Chronic Obstructive Lung Disease; Diagnosis of Diseases of Chronic Airflow Limitation: Diagnosis and initial treatment of Asthma, COPD and Asthma-COPD Overlap. Updated 2017. http://www.ginasthma.org/. Date last accessed: 17 Aug 2018.

7. Sin DD, Miravitlles M, Mannino DM, Soriano JB, Price D, Celli BR, Leung JM, Nakano Y, Park HY, Wark PA, Wechsler ME. What is asthma-COPD overlap syndrome? Towards a consensus definition from a round table discussion. Eur Respir J. 2016;48:664-73.

8. Postma DS, Rabe KF. The asthma-COPD overlap syndrome. Rev N Engl J Med. 2015;373:1241-9.

9. Tommola M, Ilmarinen P, Tuomisto LE, Lehtimäki L, Haanpää J, Niemelä O, Kankaanranta $\mathrm{H}$. Differences between asthma-COPD overlap syndrome and adult-onset asthma. Eur Respir J. 2017;49. https://doi.org/10.1183/13993003. 02383-2016.

10. Miravitlles M, Vogelmeier C, Roche N, Halpin D, Cardoso J, Chuchalin AG, Kankaanranta H, Sandström T, Śliwiński P, Zatloukal J, Blasi F. A review of national guidelines for management of COPD in Europe. Eur Respir J. 2016; 47:625-37.

11. Kankaanranta H, Harju T, Kilpeläinen M, Mazur W, Lehto JT, Katajisto M, Peisa T, Meinander T, Lehtimäki L. Diagnosis and pharmacotherapy of stable chronic obstructive pulmonary disease: the finnish guidelines. Basic Clin Pharmacol Toxicol. 2015;116:291-307.

12. Miravitlles M, Soler-Cataluña JJ, Calle M, Molina J, Almagro P, Quintano JA Riesco JA, Trigueros JA, Piñera P, Simón A, López-Campos JL, Soriano JB, Ancochea J. Guía Española de la EPOC (GesEPOC). Tratamiento farmacológico de la EPOC estable. Arch Bronconeumol. 2012;48:247-57.

13. Tommola M, Ilmarinen $\mathrm{P}$, Tuomisto LE, Kankaanranta $\mathrm{H}$. Concern of underdiagnosing asthma-COPD overlap syndrome if age limit of 40 years for asthma is used. Eur Respir J. 2017;50(2). https://doi.org/10.1183/ 13993003.00871-2017.

14. Kankaanranta $H$, Tuomisto $L E$, Ilmarinen $P$. Age-specific incidence of new asthma diagnoses in Finland. J Allergy Clin Immunol Pract. 2017;5:189-91.

15. Sood A, Qualls C, Schuyler M, Arynchyn A, Alvarado JH, Smith L, et al. Adult-onset asthma becomes the dominant phenotype among women by age 40 years. Ann Am Thorac Soc. 2013;10:188-97.

16. Park SY, Kim JH, Kim HJ, Seo B, Kwon OY, Chang HS, Kwon HS, Kim TB, Kim $H$, Park CS, Moon HB, Cho YS. High prevalence of asthma in elderly women: findings from a Korean National Health Database and adult asthma cohort. Allergy Asthma Immunol Res. 2018;10:387-96.

17. Appleton SL, Adams RJ, Wilson DH, Taylor AW, Ruffin RE. North West Adelaide cohort health study team. Spirometric criteria for asthma: adding further evidence to the debate. J Allergy Clin Immunol. 2005; 116:976-82

18. Cerveri I, Cazzoletti L, Corsico A, Marcon A, Niniano R, Grosso A, Ronzoni V, Accordini S, Janson C, Pin I, Siroux V, DeMarco R. The impact of cigarette smoking on asthma: a population-based international cohort study. Int Arch Allergy Immunol. 2012;158:175-83.

19. To T, Stanojevic S, Moores G, Gershon AS, Bateman ED, Cruz AA, Boulet LP Global asthma prevalence in adults: findings from the cross-sectional world health survey. BMC Public Health. 2012;12:204.

20. Thomson NC. Asthma and smoking-induced airway disease without spirometric COPD. Eur Respir J. 2017;49. https://doi.org/10.1183/13993003. 02061-2016.

21. Kankaanranta H, IImarinen P, Kankaanranta T, Tuomisto LE. Seinäjoki adult asthma study (SAAS): a protocol for a 12-year real-life follow-up study of new-onset asthma diagnosed at adult age and treated in primary and specialised care. NPJ Prim Care Respir Med. 2015;25:15042.

22. Tommola M, IImarinen $\mathrm{P}$, Tuomisto LE, Haanpää J, Kankaanranta T, Niemelä $\mathrm{O}$, Kankaanranta $\mathrm{H}$. The effect of smoking on lung function: a clinical study of adult-onset asthma. Eur Respir J. 2016;48:1298-306. 
23. Ilmarinen P, Tuomisto LE, Niemelä O, Tommola M, Haanpää J, Kankaanranta H. Cluster analysis on longitudinal data of patients with adult-onset asthma. J Allergy Clin Immunol Pract. 2017;5:967-78.

24. Tuomisto LE, IImarinen P, Niemelä O, Haanpää J, Kankaanranta T, Kankaanranta H. A 12-year prognosis of adult-onset asthma: Seinäjoki adult asthma study. Respir Med. 2016;117:223-9.

25. Viljanen AA, Halttunen PK, Kreus KE, Viljanen BC. Spirometric studies in nonsmoking, healthy adults. Scand J Clin Lab Invest Suppl. 1982;159:5-20.

26. Kim TB, Jang AS, Kwon HS, Park JS, Chang YS, Cho SH, Choi BW, Park JW, Nam DH, Yoon HJ, Cho YJ, Moon HB, Cho YS, Park CS, COREA Study Group. Identification of asthma clusters in two independent Korean adult asthma cohorts. Eur Respir J. 2013:41:1308-14.

27. Park SY, Jung HW, Lee JM, Shin B, Kim HJ, Kim MH, Song WJ, Kwon HS, Jung JW, Kim SH, Park HW, Jang AS, Chang YS, Cho YS, Cho YJ, Cho SH, Choi BW, Lee SJ, Jee SH, Choi SK, Won S, Park T, Kim C, Moon HB, Kim TB, COREA investigators. Novel trajectories for identifying asthma phenotypes: a longitudinal study in Korean asthma cohort, COREA. J Allergy Clin Immunol Pract. 2019. https://doi.org/10.1016/j.jaip.2019.02.011.

28. Park SY, Jung H, Kim JH, Seo B, Kwon OY, Choi S, Oh B, Kwon HS, Cho YS, Moon HB, Won S, Park T, Kim TB. Longitudinal analysis to better characterize asthma-COPD overlap syndrome: findings from an adult asthma cohort in Korea (COREA). Clin Exp Allergy. 2019. https://doi.org/10.1111/cea.13339.

29. Kim TB, Park CS, Bae YJ, Cho YS, Moon HB, COREA Study Group. Factors associated with severity and exacerbation of asthma: a baseline analysis of the cohort for reality and evolution of adult asthma in Korea (COREA). Ann Allergy Asthma Immunol. 2009;103:311-7.

30. Lee T, Lee YS, Bae YJ, Kim TB, Kim SO, Cho SH, Moon HB. Cohort for Reality and Evolution of adult Asthma in Korea study group (COREA study group), Cho YS. Smoking, longer disease duration and absence of rhinosinusitis are related to fixed airway obstruction in Koreans with severe asthma: findings from the COREA study. Respir Res. 2011;12:1.

31. Park HW, Song WJ, Kim SH, Park HK, Kim SH, Kwon YE, Kwon HS, Kim TB, Chang YS, Cho YS, Lee BJ, Jee YK, Jang AS, Nahm DH, Park JW, Yoon HJ, Cho YJ, Choi BW, Moon HB, Cho SH. Classification and implementation of asthma phenotypes in elderly patients. Ann Allergy Asthma Immunol. 2015; 114:18-22.

32. Kainu A, Lindqvist A, Sarna S, Lundbäck B, Sovijärvi A. FEV1 response to bronchodilation in an adult urban population. Chest. 2008;134:387-93.

33. Johannessen A, Lehmann S, Omenaas ER, Eide GE, Bakke PS, Gulsvik A. Postbronchodilator spirometry reference values in adults and implications for disease management. Am J Respir Crit Care Med. 2006;173:1316-25.

34. Reed CE. Asthma in the elderly: diagnosis and management. J Allergy Clin Immunol. 2010;126:681-7.

35. de Marco R, Marcon A, Rossi A, Antó JM, Cerveri I, Gislason T, Heinrich J, Janson C, Jarvis D, Kuenzli N, Leynaert B, Probst-Hensch N, Svanes C, Wjst M, Burney P. Asthma, COPD and overlap syndrome: a longitudinal study in young European adults. Eur Respir J. 2015;46:671-9.

36. Quanjer PH, Ruppel GL, Langhammer A, Krishna A, Mertens F, Johannessen A, Menezes AMB, Wehrmeister FC, Perez-Padilla R, Swanney MP, Tan WC Bourbeau J. Bronchodilator response in FVC is larger and more relevant than in FEV1 in severe airflow obstruction. Chest. 2017;151:1088-98.

37. Janson C, Malinovschi A, Amaral AFS, Accordini S, Bousquet J, Buist AS, Canonica GW, Dahlén B, Garcia-Aymerich J, Gnatiuc L, Kowalski ML, Patel J, Tan W, Torén K, Zuberbier T, Burney P, Jarvis D. Bronchodilator reversibility in asthma and COPD: findings from three large population studies. Eur Respir J. 2019;54(3). https://doi.org/10.1183/13993003.00561-2019.

38. de Nijs SB, Venekamp LN, Bel EH. Adult-onset asthma: is it really different? Eur Respir Rev. 2013;22:44-52.

39. Scichilone N, Callari A, Augugliaro G, Marchese M, Togias A, Bellia V. The impact of age on prevalence of positive skin prick tests and specific lgE tests. Respir Med. 2011;105:651-8.

\section{Publisher's Note}

Springer Nature remains neutral with regard to jurisdictional claims in published maps and institutional affiliations.

Ready to submit your research? Choose BMC and benefit from:
- fast, convenient online submission
- thorough peer review by experienced researchers in your field
- rapid publication on acceptance
- support for research data, including large and complex data types
- gold Open Access which fosters wider collaboration and increased citations
- maximum visibility for your research: over 100M website views per year
At BMC, research is always in progress.
Learn more biomedcentral.com/submissions

